\title{
OBSTÁCULOS ENFRENTADOS POR MULHERES MATEMÁTICAS NA ACADEMIA NO SÉCULO XX: UM ESTUDO EM SEIS BIOGRAFIAS ${ }^{1}$
}

\author{
Daniele Aparecida de Oliveira \\ Mariana Feiteiro Cavalari \\ Universidade Federal de Itajubá - UNIFEI - Brasil \\ (aceito para publicação em fevereiro de 2019)
}

\begin{abstract}
Resumo
Somente em meados do século XIX as mulheres conquistaram o direito de contribuir oficialmente para a produção do conhecimento científico. Contudo, nos anos iniciais do século XX, algumas instituições ainda negavam esse direito a elas. As mulheres que se dedicaram à Ciência e à Matemática, neste século, enfrentaram uma série de situações que se constituíram obstáculos para as suas carreiras na academia. Dessa forma, realizamos o presente estudo que teve como objetivo analisar em biografias de mulheres matemáticas do século XX, obstáculos enfrentados por elas em suas carreiras acadêmicas. Para isso, realizamos um estudo de biografias de Grace Chisholm Young, Amalie Emmy Noether, Anna Johnson Pell Wheeler, Julia Hall Bowman Robinson, Mary Ellen Rudin e Vivienne Malone-Mayes e analisamos os obstáculos enfrentados por elas no acesso à academia e desenvolvimento profissional. Estas análises indicaram como obstáculo relacionado ao acesso a existência do impedimento institucional, ainda no início do século XX. Já com relação ao desenvolvimento profissional, encontramos situações de preconceitos, impedimento institucional e os confrontos entre vida pessoal e profissional. Identificamos que alguns desses elementos levantados nas análises foram se modificando juntamente com a sociedade e passaram a assumir diferentes significados ao longo do século XX. Dessa forma, entendemos que os obstáculos às carreiras das mulheres matemáticas também se modificaram com o passar dos anos.
\end{abstract}

Palavras-chave: Matemática, História, Mulheres na Matemática, Século XX.

\section{[OBSTACLES FACED BY MATHEMATICIANS WOMEN IN ACADEMIA IN TWENTIETH CENTURY: A STUDY IN SIX BIOGRAPHIES]}

\begin{abstract}
Only in the mid-nineteenth century women gained the right of contributing officially for the improvement of scientific knowledge. However, at the beginning of the twentieth century,

\footnotetext{
${ }^{1}$ Este artigo apresenta resultados do Trabalho Final de Graduação intitulado "O século de ouro para as mulheres na Matemática: Um estudo de questões de gênero em biografias de algumas mulheres que se dedicaram à
} Matemática no século XX”, realizado na UNIFEI e orientado pela professora Dra. Mariana Feiteiro Cavalari.
\end{abstract}


some institutions still denied this right to them. Women who dedicated to science and Mathematics in this century faced a series of situations that obstacles their careers in academia, this way, we conducted the present study that had as objective analyze, in biographies of mathematicians women from the twentieth century, the obstacles faced by them in their academic careers. For that, we conducted a study of the biographies of Grace Chisholm Young, Amalie Emmy Noether, Anna Johnson Pell Wheeler, Julia Hall Bowman Robinson, Mary Ellen Rudin, and Vivienne Malone-Mayes and we analyzed the obstacles they faced in accessing academic and professional development. These analyses indicated the institutional impediment access as a barrier, even in the early twentieth century. Already in relation to professional development, we identified situations of prejudice, institutional impediment and confrontations between personal and professional life. We could identify that some elements pointed out in these analyses changed with the society and started to assume different meanings throughout the twentieth century. This way, we understood that obstacles to math women's careers have also changed over the years.

Keywords: Mathematics, History, Women in Mathematics, Twentieth Century.

\section{Introdução}

Árduos caminhos foram trilhados pelas mulheres para conquistar o direito de atuar na produção do conhecimento científico e, somente no final do século XIX, após os movimentos feministas das décadas de 1870 e 1880, essa condição começou a mudar. No entanto, a inserção das mulheres nas universidades ocorreu lentamente (SCHIEBINGER, 2001) e muitas tiveram que enfrentar algumas barreiras para ter acesso ao ambiente acadêmico, bem como para se desenvolverem profissionalmente.

Neste contexto, as mulheres também estiveram ausentes por muito tempo da História da Ciência. O interesse em resgatar as contribuições femininas, de acordo com Tabak (2002), despontou a partir de 1970, apoiado em projetos de historiadores feministas que ensejavam compensar a sua ausência nos estudos tradicionais. Para esta autora, em um primeiro momento, foi dada atenção às biografias de cientistas famosas e, posteriormente, os historiadores começaram a estudar a vida e os esforços de mulheres que não se tornaram famosas com o intento de expor os problemas enfrentados por elas no mundo masculino da Ciência.

A partir da década de 1990, muitos desses trabalhos biográficos passaram a ser realizados de forma a contextualizar a vida e obra do biografado (TRINDADE, BELTRAN, TONETTO, 2016) e, dessa forma, passaram a apresentar, também, ainda que como pano de fundo, movimentos culturais, políticos e intelectuais (TERRAL, 2006). Para Camerini (1997), além de ajudar a compreender a vida na Ciência, uma biografia científica também pode auxiliar na compreensão da natureza e construção do conhecimento científico.

Assim, com base nas argumentações de Tabak (2002), Trindade, Beltran e Tonetto (2016) e Terral (2006), entendemos que esse gênero textual pode ser uma importante fonte de informações para investigações que têm como foco compreender como e, sob quais circunstâncias, foram feitas as contribuições femininas em determinadas áreas da Ciência. 
Neste contexto, o presente artigo tem como objetivo analisar, em biografias de mulheres matemáticas do século XX, obstáculos enfrentados por elas em suas carreiras acadêmicas. Entendemos obstáculos em uma carreira profissional, na mesma perspectiva de Lent et al. (2000), como variáveis "extra-person", ou seja, como eventos que independem do indivíduo e não podem ser controlados por ele e que, de alguma forma, restringem o desenvolvimento de sua carreira.

Nosso foco no século XX se justifica pelo fato de que este foi, em muitos países, o período posterior à conquista das mulheres ao direito de ingressar no ambiente acadêmico e, consequentemente, foi marcado pelo crescente número de mulheres que adentraram nessa área (OSEN, 1994).

Nesse sentido, na presente investigação, buscamos, com base nas biografias estudadas, responder às seguintes questões: Que obstáculos estas mulheres enfrentaram para ingressar na carreira acadêmica de Matemática? Que obstáculos elas enfrentaram no desenvolvimento de suas carreiras?

Procedemos em três etapas para realizar este trabalho. Na primeira, realizamos a seleção das mulheres, que se dedicaram à Matemática, cujas biografias seriam analisadas, sendo estas, Grace Chisholm Young (1869-1944), Amalie Emmy Noether (1882-1935), Anna Johnson Pell Wheeler (1883-1966), Julia Hall Bowman Robinson (1919-1985), Mary Ellen Rudin (1924-2013) e Vivienne Malone-Mayes (1932-1995).

Estas foram selecionadas considerando o critério de terem vivido e realizado seus trabalhos durante o século $\mathrm{XX}^{2}$ e não estarem mais vivas, pois, assim, poderíamos analisar suas vidas e obras de forma completa. Foram selecionadas mulheres que viveram em diferentes períodos do século XX, pois, nas primeiras décadas do século XX a Ciência era culturalmente definida como imprópria para a mulher (CHASSOT, 2017) e, com o passar dos anos, essa ideia foi sendo modificada. Além disto, em perspectiva semelhante à de Henrion (1997), as matemáticas foram escolhidas de modo a representarem a diversidade daquelas que se dedicaram à Matemática no que diz respeito às suas áreas de trabalho, etnias e situações pessoais e profissionais. Da mesma forma que a referida autora, ressaltamos que a seleção dessas matemáticas não teve a intenção de indicar aquelas que mais se destacaram nesse período.

$\mathrm{Na}$ segunda etapa, realizamos uma pesquisa histórica bibliográfica voltada ao estudo de biografias destas mulheres, utilizando como fonte de informações os sítios eletrônicos MacTutor History of Mathematics archive ${ }^{3}$ e Biographies of Women Mathematicians ${ }^{4}$, além de livros e artigos científicos.

A terceira etapa desta pesquisa foi idealizada a partir do trabalho de Henrion $(1997)^{5}$, e foi constituída pela análise de biografias destas mulheres com vistas a identificar os obstáculos enfrentados por elas em suas carreiras acadêmicas.

\footnotetext{
${ }^{2}$ Não necessariamente toda a vida da matemática deveria ter sido no século XX. Então consideramos mulheres que nasceram no século XIX, e mulheres que viveram no século XXI.

${ }^{3}$ Disponível em <http://www-history.mcs.st-andrews.ac.uk/index.html>

${ }^{4}$ Disponível em: < https://www.agnesscott.edu/lriddle/women/women.htm>.

${ }^{5}$ Nessa obra de 1997, Claudia Henrion apresenta cinco mitos, divididos em seis capítulos, relacionados à imagem do matemático e à natureza da matemática. Ao final de cada um dos cinco primeiros capítulos, são apresentadas duas biografias de matemáticas estadunidenses, cujas vidas se relacionam com o mito apresentado.
} 
Para apresentar os resultados desta investigação, o presente artigo se divide em duas seções. A primeira é constituída de breves biografias das seis acadêmicas abordadas e, na segunda, apresentamos considerações acerca dos obstáculos enfrentados por elas em suas carreiras profissionais que emergem de suas biografias.

\section{Breves biografias de seis mulheres matemáticas do século $\mathrm{XX}$}

Nessa seção apresentamos sucintas biografias de seis mulheres que contribuíram para a construção do conhecimento matemático, são elas: Grace Chisholm Young, Amalie Emmy Noether, Anna Johnson Pell Wheeler, Julia Hall Bowman Robinson, Mary Ellen Rudin e Vivienne Malone-Mayes. Essa apresentação se faz necessária, pois mesmo com alguns trabalhos recentes, entendemos, na mesma perspectiva de Cavalari (2007), que ainda são escassas as traduções de biografias de mulheres matemáticas para língua portuguesa, em especial, das mulheres que viveram no século XX.

Ademais, em perspectiva semelhante a Cavalari (2010), entendemos que a apresentação de biografias de mulheres matemáticas pode trazer elementos para nos contrapormos ao argumento de que poucas mulheres contribuíram para o desenvolvimento da Matemática.

\subsection{Grace Chisholm Young (1869-1944)}

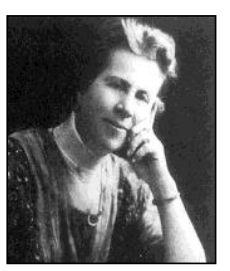

Grace Chisholm nasceu em Haslemere, uma cidade próxima à Londres, na Inglaterra. Foi educada em casa, por uma governanta, até os 17 anos. Pretendia estudar medicina, entretanto, após ser impedida pelos seus progenitores, ingressou, em 1889, no Girton College ${ }^{6}$, em Cambridge, para estudar no curso de Matemática, o qual concluiu em 1892. Continuou seus estudos em Göttingen ${ }^{7}$, que naquele momento era um centro de referência em pesquisas matemáticas, após ter o pedido de sua admissão aceito pelo Ministério da Cultura de Berlin (RIDDLE, 2017).

Em 1895, segundo Eves (2011), ela tornou-se a primeira mulher a receber um doutorado na Alemanha. Com o envelhecimento e adoecimento de seus pais, de acordo com Robertson e O'Conner (2005), Grace deixou a Alemanha e retornou para a Inglaterra para ajudar a cuidar deles. Casou-se com William Henry Young, que apesar de ser matemático, não era um pesquisador, e ela o encorajou a seguir essa carreira. Viveram por um ano na Itália e realizaram pesquisa em geometria. Dois anos depois, eles se mudaram para Göttingen onde viveram até 1908. Na universidade, foram encorajados por Klein a trabalhar com teoria dos conjuntos.

Tiveram seis filhos e se dedicaram a ensiná-los, o que resultou em muitos livros infantis para introduzir crianças na Ciência. Embora a maioria da produção matemática do casal levasse o nome de William, Grace desempenhava um papel importante na produção deles (KATZ, 2009). Estima-se que William e Grace escreveram 220 artigos matemáticos e

\footnotetext{
${ }^{6}$ Primeira instituição inglesa na qual as mulheres poderiam receber uma educação universitária (KATZ, 2009)

${ }^{7}$ Segundo Eves (2011), as escolas inglesas, nessa época, não aceitavam mulheres nos cursos de pós-graduação. 
alguns livros. Entretanto, não é possível afirmar precisamente quantos desses artigos eram de Grace Young (ROBERTSON, O'CONNER, 2005).

Em 1908, segundo Robertson e O'Conner (2005), eles se estabeleceram em Geneva, na Suíça, onde continuaram sua parceria matemática. Em 1915, a família Young se mudou para Lausanne, ainda na Suíça e em meados da década de 1920, Grace parou suas pesquisas matemáticas, pois sua saúde começou a declinar após a morte do seu filho mais velho, que servia ao exército, durante a Primeira Guerra Mundial. Quando a Segunda Guerra Mundial começou a afetar sua vida, Grace e dois de seus netos se mudaram para a Inglaterra, onde faleceu em 1944.

\subsection{Amalie Emmy Noether (1882-1935)}

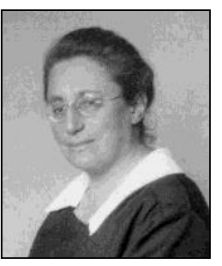

Mais conhecida como Emmy Noether, Amalie Emmy Noether nasceu na cidade de Erlanger, na Alemanha, filha do matemático Max Noether. Era a mais velha dos quatro filhos de seus pais e sua família era de origem judaica (SAITOVITCH, et al., 2015).

De 1889 a 1897, frequentou o colégio para moças Höhere Töchter Schule, em Erlangen. Inicialmente, seu objetivo era se tornar professora de línguas mas, ao invés disso, ela seguiu um caminho difícil para uma mulher na época e decidiu cursar Matemática ${ }^{8}$. Obteve permissão para acompanhar cursos na Universidade de Erlanger de 1900 a 1902 (ROBERTSON, O'CONNER, 2014b).

Em 1903, conseguiu ingressar na Universidade de Göttingen e participou de palestras de Karl Schwarzschild (1873- 1916), David Hilbert (1862-1943), Felix Klein (1849-1925) e Hermann Minkowski (1864-1909). Novamente, não tinha permissão para ser uma aluna regularmente matriculada e conseguiu apenas assistir essas palestras. Dessa forma, retornou à Erlangen um semestre depois ${ }^{9}$ e, em 1907, obteve seu doutorado sob a supervisão de Paul Gordan. A progressão normal de um posto acadêmico teria sido a habilitação. No entanto, isso não era permitido para as mulheres, então ela permaneceu em Erlangen auxiliando seu pai em questões matemáticas (ROBERTSON, O'CONNER, 2014b).

Em 1915, Hilbert e Klein fizeram o convite para que Emmy Noether retornasse à Göttingen e a persuadiram a permanecer lá enquanto lutavam para tê-la oficialmente na Universidade, pois esta instituição não permitia que mulheres ocupassem cargos acadêmicos. Em 1919, de acordo com Robertson e O'Conner (2014b), essa permissão foi concedida e lhe foi dada a posição de Privatdozent ${ }^{10}$.

Segundo Saitovitch et al. (2015), em 1922, foi concedido a ela o título de nichtbeamteter ausserordentlicher Professor (professora extraordinária não oficializada), que lhe possibilitava lecionar, mas não lhe permitia receber um salário. Dick (1980),

\footnotetext{
${ }^{8}$ As mulheres não podiam estudar nas universidades alemãs. A elas era permitido estudar não oficialmente mediante a permissão do docente em cada um dos cursos (ROBERTSON, O'CONNER, 2014).

${ }^{9}$ Segundo Robertson e O'Conner (2014), nessa época as regras tinham mudado e estudantes mulheres podiam se matricular em igualdade com os homens.

${ }^{10}$ Cargo de professor não assalariado em universidades alemãs. Era, frequentemente, um posto ocupado por matemáticos que trabalhavam para a sua Habilitação (ROBERTSON, O’CONNER, 2014).
} 
considera este como um título sem significado, pois no documento de atribuição do título constava que não haveria nenhuma mudança no seu atual cargo.

Emmy passou a receber uma pequena remuneração somente em 1923 quando recebeu o título de Lehrauftrag (Incumbência de ensino), em álgebra, resultado da pressão do Departamento de Matemática (DICK, 1980). Devido a esta situação, ela não conseguiu alcançar cargos importantes nesta universidade (SAITOVITCH et el., 2015). Lecionou em Gottingen de 1922 a 1933, com breves interrupções nos anos 1928-1929 em que foi professora visitante na Universidade de Moscou e, em Frankfurt, no verão de 1930.

Em abril de 1933, segundo Robertson e O’ Conner (2014b), as perseguições nazistas causaram sua demissão da Universidade de Göttingen. Então, Emmy Noether aceitou uma cátedra visitante no Bryn Mawr College, nos Estados Unidos, na qual foi recebida por Anna Johnson Pell Wheeler, que era chefe de matemática. Em 1934, Emmy também começou a proferir palestras semanais no Instituto de Estudos Avançados de Princeton. Em 1935, morreu nos Estados Unidos em decorrência de um tumor (ROBERTSON, O’CONNER, 2014b).

\subsection{Anna Johnson Pell Wheeler (1883-1966)}

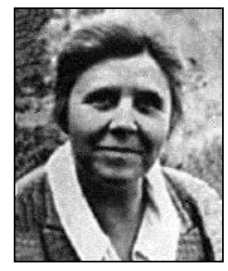

Nasceu na cidade de Calliope, nos Estados Unidos, filha de imigrantes suecos. Ingressou na Universidade de Dakota do Sul, em 1899, e se mostrou uma grande promessa para a Matemática (ROBERTSON, O'CONNER, 2014a).

Realizou, de acordo com Robertson e O'Conner (2014a), o mestrado na Universidade de Iowa em 1904, após receber um bolsa de estudos.

Durante este mestrado, Anna Johnson ganhou outra bolsa de estudo para pesquisar na Radcliffe College. Assim, realizou um segundo mestrado nessa instituição que foi premiado em 1905. Permaneceu neste College por mais um ano e foi premiada com a Alice Freeman Palmer Fellowship da Wellesley College, para estudar por um ano no exterior.

Ela foi para a Universidade de Göttingen, onde participou de palestras de David Hilbert (1862-1943), Felix Klein (1849-1925) e Hermann Minkowsi (1864-1909) e, posteriormente, trabalhou no seu doutorado sob supervisão de Hilbert. Neste período, Alexander Pell que permaneceu em contato com Anna desde o período no qual ela era sua aluna, foi à Göttingen para que eles pudessem se casar (ROBERTSON, O'CONNER, 2014a). Entretanto, segundo esses mesmos autores, casaram-se somente após o término da Bolsa Alice Freeman Palmer, pois esta exigia que o titular não se casasse durante a sua vigência.

Ao retornar aos Estados Unidos em 1907, ela lecionou em cursos de teoria das funções e equações diferenciais. Em 1908, voltou à Göttingen para completar o trabalho de seu doutorado, mas depois de um desacordo com Hilbert, retornou a Chicago em 1908 sem que o título lhe fosse concedido. Em 4 de janeiro de 1909, se matriculou na universidade de Chicago, tornou-se estudante de Eliakim Moore e recebeu o título de doutora, em 1910 (ROBERTSON, O'CONNER, 2014a). 
Ela esperava por uma boa posição na universidade, mas nesse momento havia um forte preconceito contra empregar mulheres. Em 1911, após seu marido adoecer e não encontrarem um homem para substituí-lo, o Armour Institute of Technology contratou Anna. Em 1920, morreu seu primeiro marido e, após cinco anos, casou-se com Arthur Leslie Wheeler ${ }^{11}$, esta união foi curta, já que ele morreu em 1932.

Em 1927, proferiu conferências na reunião da American Mathematical Society, sendo a primeira mulher a ter esta oportunidade. Após a morte de seu segundo marido, em 1933 ela retornou ao trabalho em tempo integral em Bryn Mawr. Nesta instituição, Emmy Noether juntou-se a ela. Segundo Robertson e O’Conner (2014a), durante seu mandato como presidente, Pell Wheeler foi fundamental para oferecer refúgio profissional e político para esta algebrista judia alemã. Faleceu em 1966, em Bryn Mawr, nos Estados Unidos.

\subsection{Julia Hall Bowman Robinson (1919-1985)}

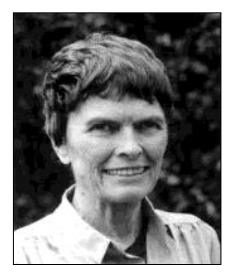

Julia Bowman nasceu em 1919, em St. Louis, Missouri. Quando tinha dois anos de idade, sua mãe faleceu e ela e sua irmã Constance Reid foram morar com uma tia em uma comunidade, no deserto do Arizona. Não havia escola no meio do deserto do Arizona, então quando Julia tinha cinco anos eles mudaram para a pequena cidade de Point Loma, em San Diego, que era habitada por cerca de cinquenta famílias e que tinha uma escola primária com tão poucos alunos que combinava crianças de diferentes idades na mesma sala. Esse arranjo permitiu que Julia progredisse mais rapidamente nos níveis escolares (ROBERTSON, O'CONNER, 2002b).

Aos nove anos de idade, Julia ficou afastada da escola por um ano devido à escarlatina. Quando ainda estava debilitada, contraiu outra doença e se mudou para a casa de uma enfermeira para passar por uma lenta recuperação que durou mais um ano. Nessa época, um tutor particular foi contratado para que Julia pudesse recuperar os conteúdos perdidos nos dois anos que esteve longe da escola (ROBERTSON, O'CONNER, 2002b).

Entre 1932 e 1933, Julia passou na escola secundária Theodore Roosevelt e depois ingressou no San Diego High School, em 1933. Quando chegou aos últimos anos, ela era a única garota nas aulas de Matemática e Física (REID, 1996). Ao ingressar na San Diego State College, de acordo com Robertson e O'Conner (2002b), Julia tinha o objetivo de estudar Matemática para ser uma professora de ensino médio, já que para ela não havia outras oportunidades de emprego para um matemático. Ademais, a maior influência no desenvolvimento matemático de Julia ocorreu através da leitura de Men of Mathematics ${ }^{12}$.

Segundo Robertson e O'Conner (2002b), infeliz com o ensino recebido na San Diego State College, Julia se transferiu para a Universidade da Califórnia, em Berkeley. Em 1940, por intermédio de Neyman, recebia uma pequena remuneração para trabalhar como assistente de ensino nessa instituição. Nessa época, ela fez um curso de teoria dos números de Raphael Robinson que, posteriormente, se tornou seu marido. Ao se casar com Raphael,

\footnotetext{
${ }^{11}$ Foi um professor de clássicos em Bryn Mawr. ${ }^{12}$ Bell (1965).
} 
em 1941, ela já não tinha permissão ${ }^{13}$ para ensinar no Departamento de Matemática. Nessa época Julia deixou a Matemática. Segundo Fernández, Contreras e Valdés (2009), nesse momento, ela não se preocupou muito com tal situação de impedimento, visto que agora ela estava casada e queria ser mãe. Pouco tempo depois Julia ficou grávida, mas sofreu um aborto.

Em 1946, de acordo com Robertson e O’Conner (2002b), foi para Princeton, onde seu marido era professor visitante. Julia retornou à Matemática, trabalhando em um doutorado sob a supervisão de Alfred Tarski (1901-1983). Em 1948, começou a trabalhar no Décimo Problema de Hilbert. Embora não tenha resolvido este problema, juntamente com Martin Davis e Hilary Putman, publicou um resultado importante que contribuiu para a solução deste, por Yuri Matijasevic em 1970.

Em 1980, Julia realizou uma conferência no Colóquio da American Mathematical Society e foi a segunda mulher a proferir conferências nesse Colóquio. Recebeu muitas honrarias em sua carreira. Foi a primeira mulher a ser eleita para a Academia Nacional de Ciências, em 1976, e ainda nesse mesmo ano, foi nomeada professora na Universidade da Califórnia, em Berkeley. Em 1978, Julia tornou-se a primeira mulher oficial da American Mathematical Society e a primeira mulher presidente dessa Sociedade, em 1982. Faleceu em 1985 e, um ano após sua morte, seu marido criou uma organização que provia bolsas de estudos em Matemática, em Berkeley, para estudantes (ROBERTSON, O'CONNER, 2002b).

\subsection{Mary Ellen Rudin (1924-2013)}

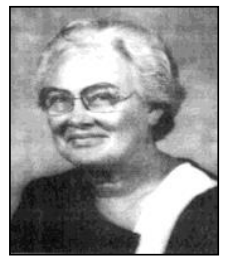

Mary Ellen foi criada em uma pequena cidade no Texas. Quando ingressou na Universidade do Texas, em 1941, não tinha ideia de quais assuntos gostaria de estudar e não tinha altas expectativas. Ademais, não se interessava por Matemática e certamente não tinha ideia de que se tornaria uma matemática (HENRION, 1997).

Ao ingressar na Universidade do Texas, segundo Henrion (1997), Mary Ellen seguiu a orientação de seus pais de seguir uma educação mais geral e, inicialmente, escolheu vários cursos. No dia de sua matrícula, conheceu Robert Lee Moore e se matriculou na sua turma de trigonometria (ROBERTSON, O'CONNER, 2008).

Segundo Robertson e O’Conner (2008), quando ela se formou em 1944, foi the oferecida uma instrução escolar em Matemática e começou a fazer pesquisas topológicas sob a supervisão de Moore para o seu doutorado. Recebeu seu PhD em 1949 e, por intermédio de Moore, recebeu um cargo de instrutora na Duke University em Durham, Carolina do Norte. Segundo Riddle (2016a), ela lecionou nesta universidade até 1953. Nesse mesmo ano, se casou com Walter Rudin e ambos foram para a Universidade de Rochester, na qual Mary Ellen trabalhou como professora assistente de 1953 a 1958.

Em 1959, Walter Rudin aceitou a nomeação de Professor Titular da Universidade de Wisconsin, em Madison. No departamento de Matemática desta universidade, um grupo de topólogos ficou interessado na pesquisa de Mary Ellen e providenciaram para que ela

${ }^{13}$ Uma norma vigente na Universidade de Berkeley na época impedia que membros de uma mesma família trabalhassem juntos em um mesmo departamento. 
fosse temporariamente nomeada como conferencista em Matemática (ROBERTSON, O'CONNER, 2008).

Mary Ellen e Walter tiveram quatro filhos, ela era uma esposa ocupada, mãe, uma pesquisadora bastante ativa e era reconhecida como uma topóloga de sucesso. Suas biografias ressaltam que esta acadêmica conseguiu conciliar o cuidado da família com os compromissos acadêmicos (RIDDLE, 2016a).

Segundo Robertson e O'Conner (2008), em agosto de 1974, ela proferiu uma série de palestras sobre topologia geral na Conference Board of the Mathematical Sciences Regional Conference Series in Mathematics, realizada na Universidade de Wyoming. Em 1981, se tornou a primeira titular da Grace Chisholm Young Professorship, em Wisconsin e permaneceu nessa instituição pelo resto de sua carreira, como professora emérita, até falecer em 2013.

\subsection{Vivienne Malone-Mayes (1932-1995)}

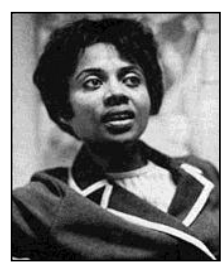

Vivienne teve um excepcional desempenho na Escola Secundária AJ Moore, racialmente segregada e se formou em 1948. Deixou a cidade de Waco, em que nasceu, para estudar na Universidade Fisk em Nashville, na qual ingressou com a intenção de obter a formação de médica (ROBERTSON, O'CONNER, 2002a).

Nessa Universidade, segundo os referidos autores, conheceu James Jeffries Mayes, que estudava odontologia. Eles decidiram se casar, mas Mayes convenceu sua futura esposa a mudar de curso. Ingressou, então, em Matemática e teve grande influência dos cursos ministrados por Evelyn Boyd Granville ${ }^{14}$.

De acordo com Robertson e O'Conner (2002a), Malone se formou em Fisk em 1952 e, logo depois, casou-se com James Jeffries Mayes. Ela realizou seu mestrado nessa mesma instituição e o concluiu em 1954. Não realizou seu doutoramento imediatamente após a conclusão do mestrado, apesar de seu marido a incentivar.

Retornou a Waco, onde foi presidente do Departamento de Matemática do Colégio Paul Quinn, operado pela Igreja Episcopal Metodista Africana, e passou sete anos nesse cargo. Em 1961, decidiu que queria estudar mais Matemática e se candidatou a estudar na Baylor University em Waco, mas a rejeitaram porque era uma afro-americana. Nesse momento, a Universidade do Texas foi obrigada pela lei federal a aceitar estudantes afroamericanos, então Malone-Mayes foi para esta instituição (RIDDLE, 2016b).

Realizou seu doutorado sob supervisão de Don Edmonson. Na pós-graduação era a única negra e a única mulher e seus colegas a ignoravam completamente. De acordo com Robertson e O'Conner (2002a), algumas aulas foram fechadas para ela, mesmo na Universidade do Texas, que era obrigada a receber estudantes afrodescendentes. Em 1966, quando recebeu seu doutorado, pela Universidade do Texas em Austin, ela se tornou a quinta mulher afro-americana a receber um doutorado em Matemática.

Depois de ter concluído o doutoramento, recebeu uma cátedra na Baylor University em Waco, que havia rejeitado sua candidatura como aluna cinco anos

${ }^{14}$ Uma das primeiras mulheres afro-americanas a receber Ph.D. em Matemática (ROBERTSON, O' CONNER, 2002a). 
antes. Vivienne se tornou a primeira professora afrodescendente dessa instituição que recebia visitas de representantes do governo que verificavam questões de salário e promoções, mas com o tempo sua posição foi se deteriorando (ROBERTSON, O'CONNER, 2002a). Depois de alguns anos doente, segundo Robertson e O' Conner (2002b), devido a uma doença inflamatória crônica se retirou da academia em 1994 e faleceu em 1995 na cidade do Texas.

\section{Obstáculos enfrentados por mulheres matemáticas no século XX}

Tendo em vista nosso objetivo de analisar obstáculos enfrentados pelas seis mulheres matemáticas abordadas nessa investigação em suas carreiras acadêmicas, optamos por dividir nossas análises em duas partes. Na primeira, foram considerados os obstáculos enfrentados por estas mulheres no acesso às universidades e, na segunda, tivemos como foco os obstáculos enfrentados por elas durante o desenvolvimento de sua carreira matemática.

O Acesso à universidade, para Henrion (1997), é crucial para a carreira acadêmica, pois consiste no primeiro passo desta carreira. Neste nível de ensino, é formada uma identidade como matemático e também podem ser feitos contatos com futuros colegas e colaboradores.

Para ter acesso ao ensino superior é necessário ter concluído a educação básica. No entanto, Cavalari (2007), após apresentar onze biografias de matemáticas em diferentes contextos históricos e geográficos, indica que poucas mulheres, somente as de famílias abastadas, tinham acesso à educação básica até o início do século XX. Neste sentido, podemos afirmar que um dos obstáculos enfrentados pelas mulheres na academia no início deste século poderia ser o acesso a todas as etapas da educação básica.

Com relação às mulheres cujas biografias foram analisadas nessa investigação, identificamos que o tipo de instrução escolar recebida estava estritamente relacionado com as condições financeiras da família. A educação domiciliar (seja por governanta ou tutor), por exemplo, esteve presente na vida de duas dessas matemáticas - Grace Young e Julia Robinson - e ambas tinham condições financeiras boas e estáveis, respectivamente. Emmy Noether estudou em um colégio exclusivo para moças e Mary Ellen Rudin em uma pequena escola que era a única mais próxima de sua casa. Já Anna Johnson e Vivienne Malone tinham condições financeiras menos favoráveis e estas frequentaram uma escola pública e uma escola racialmente segregada, respectivamente.

Apesar do fato de que essas condições econômicas e escolares pudessem representar dificuldades para o acesso à educação em nível superior, no caso de Anna Johnson, sua mãe - que não teve oportunidade de estudar - estava determinada que ela deveria receber uma boa educação. Os pais de Vivienne Malone-Mayes eram professores da educação básica e também incentivavam os estudos da filha, visto que em sua biografia, escrita por Robertson e O'Conner (2002a), é mencionado que ela ingressou na escola um ano antes do que deveria entrar. Dessa forma, podemos inferir que, nesses casos, o incentivo familiar atuou como um apoio para que elas continuassem seus estudos. Destacase, entretanto, que muitas mulheres não tiveram essas mesmas oportunidades e, de acordo com Henrion (1997), esse fator pode ter contribuído para manter muitas delas distantes da 
Matemática, pois apesar do potencial que possam ter tido, não tiveram chance de ir à escola, ou não tiveram aceitação social para fazê-lo.

Além disto, nossas análises da trajetória profissional de Emmy Noether indicam o impedimento institucional de acesso à universidade. Tal impedimento estava relacionado a não aceitação de mulheres no ambiente universitário no início do século XX na Alemanha, o que é ressaltado no seguinte excerto: "Novamente, Emmy não tinha permissão para ser uma aluna regularmente matriculada, e podia apenas assistir essas palestras" (ROBERTSON, O'CONNER, s/p., 2014b, tradução nossa ${ }^{15}$ ). Também identificamos o impedimento institucional na vida acadêmica de Vivienne Malone-Mayes que após terminar seu mestrado na Fisk University em 1954, decidiu se aprofundar nos estudos matemáticos e, em 1961, tentou ingressar na Baylor University, em Waco, nos Estados Unidos. Entretanto, sua candidatura como aluna foi rejeitada por ser afro-americana (ROBERTSON, O'CONNER, 2002a).

Podemos relacionar esses dois impedimentos ao contexto de cada época. No caso de Emmy Noether, seu impedimento estava relacionado às normas das universidades alemãs, que até 1904 não aceitavam mulheres como alunas regularmente matriculadas (ROBERTSON, O'CONNOR, 2014). Posteriormente, ela também teve dificuldades para conseguir um cargo em outra universidade alemã, a Universidade de Göttingen, pois as mulheres não podiam ocupar essa posição, como apontaremos posteriormente. Já Vivienne Malone, em um contexto de segregação racial nos Estados Unidos em que brancos e negros tinham seus lugares delimitados, sua candidatura a uma instituição predominantemente branca, de acordo com Henrion (1997), obteve como resposta que "Nós ainda não derrubamos as barreiras raciais aqui [...]" (p. 193, tradução nossa ${ }^{16}$ ). Dessa forma, podemos corroborar à Henrion (1997), que afirma que os tipos de obstáculos que as mulheres enfrentam se modificam com o tempo.

Na biografia de Grace Young, por Robertson e O'Conner (2005), identificamos que sua família a impediu de estudar medicina, área de sua escolha, e após esse impedimento ela ingressou em Matemática. Embora não tenhamos acesso às razões pelas quais ela foi impedida de estudar medicina, destacamos que no contexto dessa época, final do século XIX, não era considerado adequado uma mulher trabalhar em uma profissão da esfera pública e muitos pais restringiam as opções de carreira de suas filhas. Tal situação, neste período, pode ter contribuído para que algumas mulheres tenham mudado suas aspirações profissionais e que outras sequer tenham cursado o ensino superior.

Questões relacionadas à imagem do matemático, que nesse momento era marcadamente masculina, também podem ter desestimulado muitas mulheres a ingressarem nessa carreira devido a não identificação com essa representação. Henrion (1997), afirma que a forma de conceber a motivação na Matemática é influenciada pela imagem que temos dos matemáticos como seres autônomos e autossuficientes. Dessa forma, a dependência de forças externas de motivação poderia ser vista como uma fraqueza. Essa mesma autora afirma que, frequentemente, a afeição pela Matemática não é suficiente para a decisão de se

\footnotetext{
${ }^{15}$ Oferecemos o trecho original: "Again she was not allowed to be a properly matriculated student but was only allowed to sit in on lectures."

${ }^{16}$ Oferecemos o trecho original: "We have not yet taken down the racial barrier here $[\ldots]$ ".
} 
dedicar a esta carreira, de forma que não é incomum a motivação externa desencadeada por outra pessoa, como por exemplo, um professor ou membro da família, ser determinante nesta escolha profissional. Nota-se que esse é o caso de quatro das seis matemáticas abordadas nesse trabalho (Emmy Noether, Ana Johnson, Mary Ellen e Vivienne Malone), em que as influências ou motivações para que estas ingressassem ou continuassem seus estudos matemáticos podem ter vindo de seus professores e professoras.

De forma especial, no caso de Vivienne, entendemos que o fato de sua professora ser uma das primeiras mulheres afro-americanas a receber um Ph.D., pode ter tido grande peso para que esta ingressasse nesse mesmo caminho, já que não havia muitos exemplos de mulheres matemáticas afrodescendentes nas quais ela poderia se espelhar. Esse incentivo também foi importante porque, para muitas pessoas neste período, a Matemática não era um caminho viável para afrodescentes (HENRION, 1997).

A falta de informações sobre a natureza da Matemática e a carreira matemática também são obstáculos que possivelmente muitas mulheres encontraram. Julia Robinson, por exemplo, demonstrava desconhecimento das possibilidades da profissão, pois, inicialmente, acreditava que ao se formar a única opção de trabalho seria na educação básica. Possivelmente, o desconhecimento da profissão também se fez presente no momento inicial da carreira acadêmica de Mary Ellen Rudin, já que é recorrente em suas biografias a questão de indecisões e falta de expectativas com relação à matemática. Acreditamos que o contexto no qual ela cresceu, assim como Julia Robinson, também tenha contribuído para essa falta de informações sobre a carreira matemática.

Após ter acesso ao ensino superior, as mulheres que se interessavam pela carreira científica e que optavam por segui-la, ao buscar a profissionalização, encontravam diversas formas de preconceito e desconfiança em relação à sua capacidade (BARROSO, 1975). Não muito raramente, elas tinham que explicar sua presença em cursos de Matemática, pois não era considerado natural que mulheres fizessem tais cursos (HENRION, 1997). Nesse sentido, buscamos analisar os obstáculos enfrentados pelas seis matemáticas investigadas no Desenvolvimento acadêmico em um campo tradicionalmente masculino, como a Matemática.

Com base nas informações biográficas destas matemáticas, encontramos elementos para corroborar a Schiebinger (2001) que afirma que as universidades não foram boas para as mulheres. Assim, no que se refere ao desenvolvimento profissional, podemos apontar que identificamos nas biografias das mulheres que nos dedicamos a investigar, obstáculos como a existência de preconceitos, impedimentos instituiconais e também os confrontos entre a vida profissional e pessoal.

Na biografia de Anna Johnson, podemos identificar que após receber o título de doutora em 1910, ela esperava receber um cargo em uma boa universidade, mas acreditava que nessa época existia um forte preconceito contra o empregar mulheres. É mencionado em sua biografia, elaborada por Robertson e O'Conner (2014a), que ela acreditava que as universidades davam prioridade aos homens, mesmo estes sendo inferiores tanto na pesquisa, quanto no ensino.

Anna conseguiu um cargo no Armour Institute of Technology, em 1911, após seu marido ficar impossibilitado de lecionar nessa instituição devido a sua saúde. Sobre isso, apresentamos o seguinte trecho de uma carta escrita por Anna: 
O Sr. Pell estava doente e eles foram praticamente obrigados a me levar porque não conseguiram um homem. [...] Tenho quinze horas de disciplinas em Matemática e mostrei que uma mulher é capaz de fazer o trabalho de um homem em uma escola técnica. Os matemáticos da Universidade de Chicago ficaram muito satisfeitos pelo fato de que, por fim, uma mulher teve a chance de mostrar sua habilidade em um lugar como o Armour Institute. Mas eu sei que vai levar um grande número de anos, para quebrar o preconceito. (PELL WHEELER, 1910c apud ROBERTSON, O'CONNOR, s/p., 2014a, Tradução nossa ${ }^{17}$ ).

A carreira acadêmica de Emmy Noether também foi marcada pelo impedimento institucional. Robertson e O'Conner (2014b), mencionam que Emmy não conseguiu progredir normalmente academicamente após o seu doutoramento. Ela concluiu o doutorado em 1907, mas somente em 1919 conseguiu seu primeiro cargo oficial na Universidade de Gottingen. Dick (1980) afirma que, de acordo com o regulamento, a Habilitação - que seria a progressão normal de um posto acadêmico - somente poderia ser concedida a candidatos homens. Sobre os impedimentos na vida acadêmica de Emmy

O que ficou marcado, em sua história de vida, foi a constatação de que, apesar de todo o sucesso acadêmico e do reconhecimento de ser ela grande matemática, não conseguiu atingir cargos importantes na mencionada universidade [...] (SAITOVITCH, et al., 2015, p. 37).

Já Vivienne Malone-Mayes enfrentou a exclusão no ambiente universitário, que ia além do preconceito por ela ser uma mulher matemática, pois ela era afrodescendente. $\mathrm{O}$ seguinte excerto exemplifica uma situação recorrente na vida acadêmica de Malone-Mayes: "Seus colegas de classe a ignoravam completamente, até mesmo encerrando as conversas se ela estivesse ao alcance de ouvir" (ROBERTSON, O'CONNER, s/p., 2002a, tradução nossa $\left.{ }^{18}\right)$. No contexto estadunidense da década de 1960, ainda havia grande discriminação racial em instituições acadêmicas (HENRION, 1997). Vivienne também teve dificuldades para conseguir um emprego e, ironicamente, após ter concluído seu doutorado, recebeu uma cátedra na Baylor University, que havia a rejeitado como aluna alguns anos antes.

Esta universidade recebia anualmente visitas de representantes do governo que verificavam questões de salários e promoções para determinar se ela poderia estar sujeita a qualquer tipo de discriminação (ROBERTSON, O'CONNER, 2002a). Quando essas visitas terminaram, a sua posição foi se deteriorando. Apesar de sofrerem preconceito em dobro

\footnotetext{
${ }^{17}$ Oferecemos o trecho original: "Mr Pell was sick and they were practically forced to take me for they could not get a man. [...] I have fifteen hours of subjects in Mathematics and have shown them that a woman is capable of doing a man's work in a technical school. The mathematics men at the University of Chicago were very much pleased that at least a woman had the chance to show her ability in such a place as the Armour Institute. But I know it will take a great number of years, to break down the prejudice".

${ }^{18}$ Oferecemos o trecho original: "Her classmates ignored her completely, even terminating conversations if she came within earshot" (ROBERTSON, O'CONNER, 2002).
} 
pelo seu gênero e raça, mulheres como Vivienne Malone-Mayes enfrentavam essas adversidades como forma de abrir portas de possibilidades para minorias de estudantes (HENRION, 1997).

Esse modo de enfrentar os obstáculos encontrados na carreira acadêmica para que outras mulheres também o fizessem, pode ter sido um incentivo a mais para que essas mulheres prosseguissem. Assim como Vivienne, possivelmente, Julia Robinson acreditava que o pioneirismo de algumas delas poderia ajudar ou motivar outras a seguirem o mesmo caminho. Em sua biografia, por Fernández, Conreras e Valdés (2009), é mencionado que ela não aceitou o cargo de presidente da American Mathematical Society imediatamente, mas uma das razões que levaram Julia a aceitar posteriormente, foi o fato de que uma mulher nunca havia sido presidente desta sociedade e caso ela não aceitasse, poderia passar muito tempo até que fosse oferecido o cargo novamente a uma mulher.

Podemos inferir que Julia Robinson achava necessário esse apoio como forma de incentivar mais mulheres à carreira matemática. Ela acreditava que não havia razão para que elas não pudessem ser matemáticas, e afirmava que deveriam existir ações para levar mais mulheres para faculdades de Matemática. Reid (1996, p. 1492, tradução nossa ${ }^{19}$ ) apresenta uma ideia de Robinson sobre a participação feminina na Matemática, apresentada em sua última entrevista a ela: "Se nós não mudamos nada, então nada irá mudar". Dessa forma, entendemos que sabendo das dificuldades enfrentadas por uma mulher para ter seus trabalhos reconhecidos pela comunidade matemática, e pela pouca representatividade que estas tinham, Julia aceitou o cargo de presidente da American Mathematical Society.

O preconceito contra as mulheres no ambiente acadêmico, em diversos momentos na história, levou muitas delas a abandonarem seus atavios de feminilidade como uma forma de aumentar sua credibilidade como matemática. Schiebinger (2001) afirma que esse abandono "[...] não só é geralmente necessário para uma mulher ser levada a sério como cientista, mas é com frequência importante também para evitar atenção indesejável à sua sexualidade.” (p. 152). Na biografia de Emmy Noether, por August Dick (1981, p. 22), identificamos a seguinte descrição do neto do matemático Franz Mertens ${ }^{20}$, ao recordar de uma visita de Emmy ao seu avô.

[...] apesar de ser uma mulher [ela] parecia um capelão católico de uma paróquia rural - vestida com um casaco preto, quase no comprimento do tornozelo e bastante indescritivel, um chapéu de homem sobre seus cabelos curtos... e com uma bolsa de ombro carregada transversalmente como aquelas carregadas pelos condutores ferroviários do período imperial [...].(DICK, 1981, p. 22, Tradução nossa ${ }^{21}$ ).

Dick (1981) afirma, ainda, que Emmy usava sapatos tão robustos que não poderia ser evitada a impressão de que eles eram masculinos. Schiebinger (2001) relata que Emmy

\footnotetext{
${ }^{19}$ Oferecemos o trecho original: "If we do not change anything, then nothing will change."

${ }^{20}$ Matemático nascido em 1840 na Prússia (atualmente Polônia). Realizou seus estudos na Universidade de Berlim, onde obteve seu doutorado em 1865 sob a supervisão de Kummer e Kronecker (ROBERTSON, O'CONNER, 2006)

${ }^{21}$ Oferecemos o trecho original: "[...] although a woman, seemed to me like a Catholic chaplain from a rural parish - dressed in a black, almost ankle-lenght, and rather nondescript coat, a man's hat on her short hair... and with a shoulder bag carried crosswise like those of the railroad conductors during the imperial period [...]."
} 
era afetuosamente chamada de "der Noether", sendo que "der" constitui um pronome masculino. Isso ocorria não somente por Emmy ser de constituição pesada e voz forte, mas por ser uma pessoa tão criativa que parecia ter rompido a barreira do sexo. Para Schiebinger (2001, p. 154) em épocas passadas, “[...] o maior cumprimento a uma mulher de Ciência era torná-la um homem honorário."

No que diz respeito aos obstáculos envolvendo conflitos entre vida pessoal e profissional, podemos identificar situações em que ideais e decisões relativas à vida particular das mulheres influenciaram em suas carreiras. Identificamos essas questões em biografias de Grace Young, Emmy Noether, Julia Robinson e Anna Johnson.

Anna Johnson, na condição de bolsista da Alice Freeman Palmer, não poderia se casar, visto que era uma exigência que o titular não se casasse durante a sua vigência. Dessa forma, Anna e seu marido se casaram após o término dessa bolsa.

No caso de Emmy Noether, destacamos o seguinte trecho: "Em abril de 1933, as conquistas matemáticas de Emmy não valeram de nada quando as perseguições nazistas causaram sua demissão da Universidade de Göttingen porque ela era judia" (ROBERTSON, O’CONNOR, s/p., 2014b, tradução nossa ${ }^{22}$ ).

No caso de Julia Robinson, esta não pode mais ensinar no departamento de Matemática depois de ter se casado com Raphael Robinson. Segundo as normas da Universidade de Berkeley dessa época, pessoas de uma mesma família não poderiam ensinar no mesmo departamento e como Raphael trabalhava há mais tempo nessa universidade, Julia só tinha permissão para lecionar estatística.

Em todos esses casos, percebemos que situações e decisões relativas à vida particular e profissional das matemáticas, em algum momento, entraram em confronto. Possivelmente, no contexto da situação de Emmy Noether, sua demissão independeu de seu gênero, visto que homens judeus também sofreram com tal situação. No entanto, conforme citado por Osen (1994), Emmy tinha três pontos contra ela, pois ela era mulher, judia e liberal, de forma que sua demissão poderia até mesmo já ser prevista.

Quanto à norma da Universidade de Berkeley que impedia familiares de trabalharem no mesmo departamento, Fernández, Contreras e Valdés (2009) afirmam que não se pode dizer que esse foi um caso de discriminação por Julia ser mulher, pois o mesmo se aplicaria à Raphael caso Julia tivesse começado a trabalhar primeiro nessa universidade. No entanto, esses autores afirmam que a probabilidade de ocorrência seria muito menor nesse caso.

Outro ponto relevante nas biografias estudadas consiste na dificuldade de reformulação da organização familiar. Á medida que a Ciência se profissionalizou ela migrou para a esfera pública da sociedade, ao mesmo passo que a família se deslocou para a esfera doméstica privada. Os homens (da elite e da classe-média) encontraram seu lugar "natural" na esfera pública, enquanto as mulheres deveriam ocupar o cargo de mãe dentro do lar (SCHIEBINGER, 2001).

Assim, a esfera pública, e consequentemente, o ambiente acadêmico não eram considerados lugares adequados para as mulheres, visto que a elas cabiam os cuidados com

${ }^{22}$ Oferecemos o trecho original: "In April 1933 her mathematical achievements counted for nothing when the Nazis caused her dismissal from the University of Göttingen because she was Jewish."

RBHM, Vol. 19, n 28, p. 1-21, 2019 
o lar e a família. Entretanto, para Amaral (2012), o ingresso feminino no mercado de trabalho, na esfera pública, gerou modificações sociais nesse campo e surgiu o desafio da reformulação da organização familiar para que homens e mulheres tivessem responsabilidades profissionais e domésticas iguais.

Na biografia de Julia Robinson, elaborada por Constance Reid (1996), é afirmado que ao aceitar o cargo de presidente da American Mathematical Society, seu marido teve que assumir algumas dessas responsabilidades para que Julia pudesse se dedicar à sua carreira. Isso pode ser identificado ao ser mencionado que "[...] Raphael aceitou a decisão de Julia com graça, cozinhando e cuidando dele mesmo durante suas várias ausências" (REID, 1996, p. 1490, tradução nossa ${ }^{23}$ ). Neste trecho podemos notar que, neste momento de sua carreira, ela contou com a ajuda de seu companheiro no desenvolvimento de algumas tarefas domésticas. Tal situação pode mostrar que embora contasse com este auxílio, era ela quem se responsabilizava pelas tarefas domésticas. Sendo assim, entendemos que mesmo nos melhores casos, em que as mulheres contavam com a ajuda de seus parceiros, os afazeres domésticos ainda eram entendidos como encargos femininos.

A dedicação à maternidade, em alguns casos, também pode representar um obstáculo ao desenvolvimento profissional das mulheres. Dentre as seis matemáticas que foram abordadas neste trabalho, duas delas eram mães, sendo estas, Grace Chisholm Young, que teve seis filhos e Mary Ellen Rudin que teve quatro.

Com relação à Grace Young, a maternidade pode ser notada em sua biografia escrita por Robertson e O'Conner (2005), quando é mencionado o fato de que ao educar seus filhos, ela e seu marido escreveram muitos livros infantis. Também é dado destaque ao fato de que ela escreveu, sozinha, dois outros livros para introduzir crianças na Ciência. Dessa forma, entendemos que, possivelmente, Grace se dedicava mais à educação dos seus filhos que seu marido. Outro elemento que nos induz a essa inferência diz respeito a um trecho de uma carta escrita por seu marido destinada a ela, na qual ele menciona que "No momento você não pode assumir uma carreira pública. Você tem seus filhos. Eu posso e faço" (ROBERTSON, O’ CONNOR, s/p, 2005, tradução nossa ${ }^{24}$ ). Quanto à conciliação de suas pesquisas matemáticas com a maternidade, como ela e seu marido trabalhavam juntos, não podemos afirmar quanto desse trabalho era feito por Grace.

Entendemos que a pressão para que a mulher exerça seu papel de esposa e mãe, possivelmente manteve - e ainda mantém - muitas mulheres longe dos círculos científicos. Schiebinger (2001) argumenta que isso se deve ao fato de que a sociedade espera que as mulheres, mais do que os homens, coloquem a família à frente da carreira.

Já na biografia de Julia Robinson, elaborada por Fernández, Contreras e Valdés (2009), encontramos informações de que, quando foi impedida de lecionar no Departamento de Matemática da Universidade de Berkeley, ela achava que aquele era o momento para ter filhos. Acreditamos que o fato dela querer aproveitar esse impedimento em sua carreira para se dedicar à maternidade, indica, de certo modo, que Julia Robinson considerava difícil a conciliação dessas duas atividades.

${ }^{23}$ Oferecemos o trecho original: “[...] Raphael accepted Julia's decision with grace, cooking and take care of him during his many abscences."

${ }^{24}$ Oferecemos o trecho original: "At presente you cannot undertke a public career. You have your children. I can and do." 
Entendemos que a relação entre carreira científica e maternidade é complexa, pois como afirma Schiebinger (2001), "[...] os anos de 22 a 40, são cruciais para o estabelecimento de uma carreira de sucesso, também são os principais anos para o parto" (p. 185). Além disto, de acordo com Henrion (1997), se as mulheres "[...] devotam suas vidas à Matemática, observando as prioridades de sua profissão, elas são julgadas severamente como mulheres. Se elas abraçam mais responsabilidades, ou papéis típicos por terem uma família, elas não são vistas como matemáticas sérias." (p. 69, Tradução nossa ${ }^{25}$ )

No caso de Mary Ellen Rudin, mesmo tendo uma babá para cuidar dos seus filhos, ela estava sempre presente na educação das crianças e por isso trabalhava em casa. Henrion (1997), afirma que, para Mary Ellen, ser esposa e mãe era tão importante quanto ser uma matemática. Seu caso pode ser mencionado como um exemplo no que diz respeito à conciliação de carreira matemática e maternidade sem muitas dificuldades, pois, comumente, as mulheres vivenciavam dilemas e/ou se viam obrigadas a fazer uma escolha entre essas duas opções. No seu caso, o fato de sua condição financeira permitir que uma babá fosse contratada para ajudar a cuidar dos filhos, certamente lhe dava mais tempo para se dedicar às suas pesquisas (HENRION, 1997).

Muitas mulheres que tentam conciliar a maternidade à carreira, ao voltar após um período de licença maternidade, se deparam com o fato de que a Ciência é um empreendimento que progride rapidamente e que ao se afastarem por algum tempo dela para se dedicarem à maternidade, elas poderiam gastar até o dobro de tempo para retomar seus estudos e se atualizar (CHASSOT, 2017). Dessa forma, muitas mulheres se sentiam desmotivadas a voltar para o trabalho após terem seus filhos e desistiam da carreira.

A maternidade também pode simbolizar um impedimento para realizar viagens de trabalho, o que tornaria mais difícil o estabelecimento de contato com outros matemáticos e com a comunidade matemática, que é considerado um elemento importante para o progresso na carreira. A questão do marido de Mary Ellen também ser um matemático é um fator que pode ter contribuído para facilitar a sua relação com essa comunidade, de modo que ela poderia construir contatos científicos em sua própria casa (HENRION, 1997).

O fato de Mary Ellen Rudin, Grace Young, Anna Johnson e Julia Robinson, ou seja, quatro das seis mulheres estudadas, terem sido casadas com matemáticos, nos chamou atenção. De acordo com Schiebinger (2008), cerca de 70\% das matemáticas têm como parceiros, homens que também se dedicam à carreira matemática. Essa mesma autora, citando Cole e Zuckerman, menciona que mulheres cientistas que se casam com um homem do mesmo campo profissional, publicam $40 \%$ a mais do que mulheres casadas com homens em campos não científicos. Para Schiebinger (2001), supostamente pode existir uma relação entre a intensificação da produtividade dessas mulheres com o acesso aos contatos profissionais dos seus maridos.

No entanto, em alguns casos como o de Grace Young, podemos identificar na colaboração matemática entre cônjuges obstáculos com relação ao reconhecimento pela autoria dos trabalhos desenvolvidos. Conforme descrito por Robertson e O’Conner (2005),

${ }^{25}$ Oferecemos o trecho original: "[...] devoted their lives to mathematics, observing the priorities of their profession, they were judged harshly as women. If they embraced more typical responsabilities or roles by having a family, they were not seen as serious mathematicians." 
os trabalhos frutos da colaboração de Grace com seu marido Willian Young, em sua maioria, foram publicados apenas com o nome dele, mesmo ela tendo feito importantes contribuições.

Henrion (1997) afirma que muitas mulheres, em especial nos anos iniciais do século XX, trabalhavam com seus maridos ou colegas homens, e que, frequentemente, essa era a única forma de ter acesso a materiais e equipamentos necessários para o desenvolvimento de pesquisas.

Dessa forma, Schiebinger (2001) aponta que estudos de historiadores mostraram que a colaboração entre maridos e esposas, serviu como um caminho informal para a Ciência, especialmente para as mulheres. Ressalta ainda que, tipicamente, era o homem quem era lembrado e citado pelo trabalho, e que em casos mais extremos, assim como o de Grace, o nome da mulher matemática não era mencionado e, dessa forma, elas se tornavam invisíveis. Apesar disso, enfatizamos que a colaboração matemática de cônjuges, assim como o impedimento das mulheres na carreira científica, adquiriram diferentes significados ao longo do século XX. Se inicialmente, em alguns casos, essa colaboração ocultava a figura feminina, posteriormente passou a ser uma forma dos seus trabalhos ganharem mais notabilidade e, também, um caminho para a aceitação na área.

Além dos obstáculos que pudemos identificar na análise das biografias destas seis mulheres, ressaltamos que muitos outros podem ter surgido em algum momento da vida dessas mulheres ${ }^{26}$, assim como na vida de outras, que não foram abordadas nesse trabalho. Destacamos, ainda, que a maioria dos obstáculos apresentados estão relacionados ao gênero. De acordo com Henrion (1997), questões de gênero ainda dificultam a aceitação completa das mulheres como matemáticas. No entanto, não se pode mais falar do impedimento explícito para ingressar na carreira, por exemplo. Ressaltamos que vivemos em uma sociedade em constante transformação, e neste contexto, os obstáculos impostos às carreiras de mulheres cientistas também se transformam.

Dessa forma, entendemos que barreiras podem continuar a existir no século XXI de formas mais sutis, sendo incorporadas em atitudes e crenças ou até mesmo em expectativas. Elementos da própria cultura que parecem ingênuos, como por exemplo, dar aos meninos brinquedos que permitem construção, montagem e raciocínio lógico, enquanto que às meninas são dados brinquedos relacionados aos cuidados domésticos e familiares, criam aspirações de carreiras e estimulam certos comportamentos em detrimento de outros (SCHIEBINGER, 2001).

Por fim, assim como afirma Chassot (2017), ressaltamos que grande parte do que conhecemos é fruto de uma história humanamente construída e, portanto, falível. Dessa forma, cabe a nós, agentes dessa construção, fazermos modificações. Somente assim estaremos tentando descontruir preconceitos milenares que não se desconstruirão em duas ou três gerações e que ainda refletem na carreira de mulheres matemáticas.

${ }^{26}$ Afinal concordamos com Trindade, Beltran, Tonetto (2016) que afirmam que ao analisar "[...] uma biografia científica, deve-se ter claro que não é possível encontrar todos os detalhes de cada momento vivido pelo cientista numa determinada época e local.” (p. 49) 


\section{Considerações finais}

Esta investigação foi realizada com o intento de analisar, em biografias de mulheres matemáticas do século XX, obstáculos enfrentados por elas em suas carreiras acadêmicas.

Em nossas análises, identificamos obstáculos enfrentados por estas mulheres no acesso à academia e em seu desenvolvimento acadêmico. No que diz respeito ao Acesso à academia, evidenciamos a presença do impedimento institucional ainda no início do século $\mathrm{XX}$. Posteriormente, apesar de terem conquistado o direito de ingressar nas universidades e o impedimento explícito ter deixado de existir com o passar dos anos, outros fatores contribuíram para que essas mulheres trilhassem árduos e diferentes caminhos para ter acesso ao ensino superior.

Com relação ao Desenvolvimento Acadêmico, podemos citar como exemplos de obstáculos para o crescimento profissional das matemáticas a existência de preconceitos, o impedimento institucional e os confrontos entre vida profissional e pessoal. Alguns dos elementos apontados estão estritamente relacionados ao gênero e também aos valores sociais e ideológicos, que se modificaram ao longo do século XX, e podem ter contribuído para tornar o crescimento profissional dessas mulheres mais difícil e, em alguns casos, inferior aos dos homens.

Para finalizar, destacamos que este trabalho torna visível uma série de fatores que se configuraram como obstáculos na carreira acadêmica de algumas matemáticas do século $\mathrm{XX}$, que, por vezes, a história não enfatiza. Ao conhecê-los temos condições de refletir sobre a condição da mulher na Ciência, especialmente na Matemática.

\section{Bibliografia}

AMARAL, G. A. Os desafios da inserção da mulher no mercado de trabalho. Revista Eletrônica do Curso de Pedagogia do Campus Jataí, v. 2, n. 13, 2012.

BARROSO, C. A. Por que tão poucas mulheres exercem atividades científicas? Ciência e Cultura. v. 27, n. 7, p. 703-710, jul. 1975 b.

CAMERINI, J. The power of biography. Isis, v. 88, n. 2, 1997, p. $306-311$.

CAVALARI, M. F. A Matemática é feminina? Um estudo histórico da presença da mulher em Institutos de pesquisa em Matemática do Estado de São Paulo. 2007. 156 f. Dissertação (Mestrado em Educação Matemática). Universidade Estadual Paulista "Julio de Mesquita Filho" - UNESP, Rio Claro, 2007.

CAVALARI, M. F. Mulheres matemáticas: presença feminina na docência no ensino superior de Matemática das Universidades Estaduais Paulistas - Brasil. Revista Brasileira de História da Matemática, v. 10, n. 19, p. 89-102, 2010.

CHASSOT, A. I. A Ciência é masculina? É, sim senhora! $8^{\text {a }}$ Ed. São Leopoldo, Rio Grande do Sul: Editora Unisinos, 2017.

DICK, A. Emmy Noether, 1882-1935. Translated by Heide I. Blocher. Boston: Birkhauser, 1981.

EVES, H. Introdução à História da Matemática. Tradução de Higino H. Domingues. Campinas: Editora da UNICAMP, 2011. (5 EDICAO) 
FERNÁNDEZ, I. H.; CONTRERAS, C. M.; VALDÉS, J. N. Diofanto, Hilbert y Robinson: Alguna relación entre ellos? Revista de Didáctica de las Matemáticas, v. 70, p. 75-87, abr. de 2009.

HENRION, C. Women in Mathematics: The Addition of Difference. Bloomington: Indiana University Press, 1997.

KATZ, V. J. A History of Mathematics: an Introduction. . $3^{\text {a }}$ Ed. Columbia, USA: Editora Pearson Education, Inc., 2009.

LENT, R. W., BROWN, S. D. \& HACKETT, G. Contextual supports and barriers to career choice: A social-cognitive analysis. Journal of Counseling Psychology, p. 36-49, 2000.

OSEN, L. M. Women in Mathematics. Cambridge: MIT Press, 1994.

REID, Constance. Being Julia Robinson's sister. Notices of the AMS, v. 43, n. 12, 1996, p. 1486-1492.

RIDDLE, L. Mary Ellen Rudin. Disponível em: <https://www.agnesscott.edu/lriddle/women/rudin.htm> 2016a. Acesso em 11 de set. 2018.

- Vivienne Malone-Mayes. Disponível em:

<https://www.agnesscott.edu/lriddle/women/mayes2.htm>. 2016b. Acesso em 11 de set. 2018.

Grace Chisholm Young. Disponível em: https://www.agnesscott.edu/lriddle/women/young.htm> 2017. Acesso em 11 de set. 2018.

ROBERTSOn, E. F.; O’CONNER, J. J. Anna Johnson Pell Wheler. Disponível em:http://www-history.mcs.st-and.ac.uk/Biographies/Wheeler.html. 2014a. Acesso em 25 de jul. 2017.

Emmy Amalie Noether. Disponível em: http://www-history.mcs.stand.ac.uk/Biographies/Noether_Emmy.html. 2014b. Acesso em 25 de jul. 2017.

Grace Chisholm Young. Disponível em: http://www-history.mcs.stand.ac.uk/Biographies/Chisholm_Young.html. 2005. Acesso em 25 de jul. 2017.

. Julia Hall Bowman Robinson. Disponívem em: < http://www-history.mcs.stand.ac.uk/Biographies/Robinson_Julia.html>. 2002b. Acesso em 25 de jul. 2017.

. Mary Ellen Rudin. Disponível em: <http://www-history.mcs.stand.ac.uk/Biographies/Rudin.html>. 2008. Acesso em 25 de jul. 2017.

. Vivienne Malone-Mayes. Disponível em: http://www-history.mcs.stand.ac.uk/Biographies/Malone-Mayes.html. 2002a. Acesso em 25 de jul. 2017.

SAITOVITCH, E. M. B.; FUNCHAL, R. Z.; BARBOSA, M. C. B. PINHO, S. T. R.; SANTANA, A. E. (Org.). Mulheres na Física: Casos históricos, panorama e perspectivas. São Paulo: Editora Livraria da Física, 2015.

SCHIEBINGER, L. Mais mulheres na ciência: questões de conhecimento. Suplemento, v. 15, p. 269-281, jun. 2008.

(Mulher.)

. O feminismo mudou a Ciência? Trad. Raul Fiker. Bauru: EDUSC, 2001.

TABAK, F. O laboratório de Pandora: Estudos Sobre a Ciência no Feminismo. Rio de Janeiro: Garamond, 2002.

TERRAL, M. Biography as Cultural History of Science. Isis, v. 97, n. 2, 2006, p. 306-313. 
TRINDADE, L. S. P.; BELTRAN, M. H. R.; TONETTO, S. R. Práticas e estratégias femininas: histórias de mulheres nas ciências da matéria. São Paulo: Editora Livraria da Física, 2016.

\section{Daniele Aparecida de Oliveira}

Mestranda em "Educação em Ciências" na Universidade

Federal de Itajubá - UNIFEI

E-mail: daniaoliveira@outlook.com.br

\section{Mariana Feiteiro Cavalari}

Instituto de Matemática e Computação da Universidade Federal de Itajubá - UNIFEI - campus Itajubá - Brasil

E-mail: mfcavalari@unifei.edu.br 